\title{
MODELLING BUILDING COSTS FROM 3D BUILDING MODELS - ESTIMATING THE CONSTRUCTION EFFORT FROM IMAGE-BASED SURFACE MODELS OF DRY-STONE SHEPHERD SHELTERS (KRAS, SLOVENIA)
}

\author{
S. Štuhec ${ }^{\mathrm{a}, *}$, G. Verhoeven ${ }^{\mathrm{b}}$, I. Štuhec ${ }^{\mathrm{c}}$ \\ ${ }^{a}$ University of Ljubljana, Faculty of Arts, Department of Archaeology, Aškerčeva 2, 1000 Ljubljana, Slovenia, \\ seta.stuhec@gmail.com \\ ${ }^{\mathrm{b}}$ Ludwig Boltzmann Institute for Archaeological Prospection \& Virtual Archaeology, Franz-Klein-Gasse 1, 1190 Vienna, Austria \\ Geert.Verhoeven@archpro.lbg.ac.at \\ ${ }^{c}$ University of Ljubljana, Faculty of Mathematics and Physics, Department of Physics, Jadranska ulica 19, Ljubljana, Slovenia, \\ iztok.stuhec@gmail.com
}

\section{Commission II}

KEY WORDS: Architectural energetics, Biomechanics, Caloric expenditure, Dry-stone building, Image-based modelling, Slovenia

\begin{abstract}
:
In the second half of the $19^{\text {th }}$ and early $20^{\text {th }}$ century, sheep shepherds have built dry-stone shelters all over the Slovene Kras (or Karst) region. Despite being made out of stones that are interlocked without the use of any binding material, many of these vernacular constructions survived - even though sometimes only partially - the ravages of time. The fact that over one hundred fifty shepherd shelters are currently known is mainly due to the craftsmanship of their builders and thanks to (and even despite) their present location. A majority of these stone constructions can be found in areas that are nowadays forested, thus shielding them from weather-related or anthropogenic damage (because they are difficult to spot). This paper reports on the geometric documentation of those shelters using a photogrammetric computer vision pipeline, thereby mainly focussing on the difficulties that were encountered during this process. However, such image-based modelling approaches merely yield digital three-dimensional (3D) approximations of the shelters' surface geometry (along with some sub-optimal colour data). Although these 3D surface models might be suitable to digitally preserve vulnerable vernacular buildings to some extent, they do not magically advance our understanding of them. The second part of this article focuses, therefore, on the extraction of archaeological information from these digital 3D constructions. More specifically, the total amount of stones, the total building time and the building cost regarding caloric energy expenditure are estimated for each of the digitised shelters. Although this assessment of architectural energetics provided useful insight into the building efforts and nutrient uptake of the shepherds, it also revealed many assumptions and shortcomings that often characterise archaeological information extraction from digital 3D models of buildings.
\end{abstract}

\section{INTRODUCTION}

Dry-stone walling has been used since Prehistory and is today still applied in the traditional architecture of the Slovene Kras region (more commonly known as Karst region or Karst plateau). In the second half of the $19^{\text {th }}$ and the first half of the $20^{\text {th }}$ century, sheep shepherds have extensively used this technique to erect many small shelters all over the Kras region. Currently, over one hundred fifty of these dry-stone shepherd shelters are known (Juvanec, 2016).

This is remarkable because many of these stone constructions are nowadays located in forested areas. On top of that, the whole Karst landscape is characterised by millions of limestone stones, randomly spread or amalgamated over centuries in low winding dry-stone walls or stone heaps (cairns). Both factors make it often hard to find these shepherd shelters. Although this hidden character shields them from anthropogenic damage (e.g. local people looking for building material), it also impedes their exhaustive inventory. Moreover, the forest itself both protects and destroys: the large trees prevent erosion and damage by adverse weather conditions, whereas their roots penetrate and the small surrounding vegetation overgrows the shelters. Even though most shelters were not erected in forested areas, they are nowadays gradually absorbed by it.
This paper wants to report on how three-dimensional (3D) digital surface recording techniques have been used to geometrically document, inventory and research nineteen of those shepherd shelters (called pastirska hiška [singular] or pastirske hiške [plural] in Slovene - that is the reason why the shelters are numbered as HIS $\mathrm{xxx}$ ). The encompassing premise of this research project is that textured $3 \mathrm{D}$ surface models are not only well-suited for documenting such organic architecture, but that they also hold great potential for unique archaeological information extraction, even if the architecture under study is relatively simple (see also Štuhec, 2014).

After introducing this typical form of Kras architecture, the rest of the paper will, therefore, mainly focus on two topics: the digital documentation of these stone structures using 3D surface approximations and the use of the latter to estimate the temporal and metabolic building costs of the former. In other words: the time and calories needed to erect such a vernacular construction will be estimated from the detailed digital surface geometry.

\section{METHOD}

Since it is well-known that image-based modelling approaches often effectively substitute many conventional documentation

\footnotetext{
* Corresponding author. seta.stuhec@gmail.com
} 
methods in archaeology, this investigation primarily tries to assess the added value of such digital 3D surface models in gaining novel archaeological insights from these relatively simple shepherd shelters. An essential prerequisite for this information extraction is the generation of a two-manifold watertight 3D surface mesh (section 2.1). From this mesh, one can estimate the total stone volume per specific shelter (section 2.2.1), while the mean volumetric mass density of stone allows retrieving the shelter's total stone mass (section 2.2.2). With the use of these new variables, the total labour time (section 2.3.1) and caloric expenditure (section 2.3.2) can be estimated.

\subsection{Image-based modelling}

\subsubsection{Data acquisition}

The 3D digital documentation of this architecture has been a particular undertaking, since many shepherd shelters are hidden in the forest and retrieving their proper location was not without problems. Navigating to, and searching for, these shelters while carrying bulky equipment like laser scanners and total stations would thus have been very hard (Figure 1). In addition, most of these shelters feature a tiny interior space, which also impedes the use of sizeable hardware. For these practical reasons, the whole 3D documentation approach was image-based.

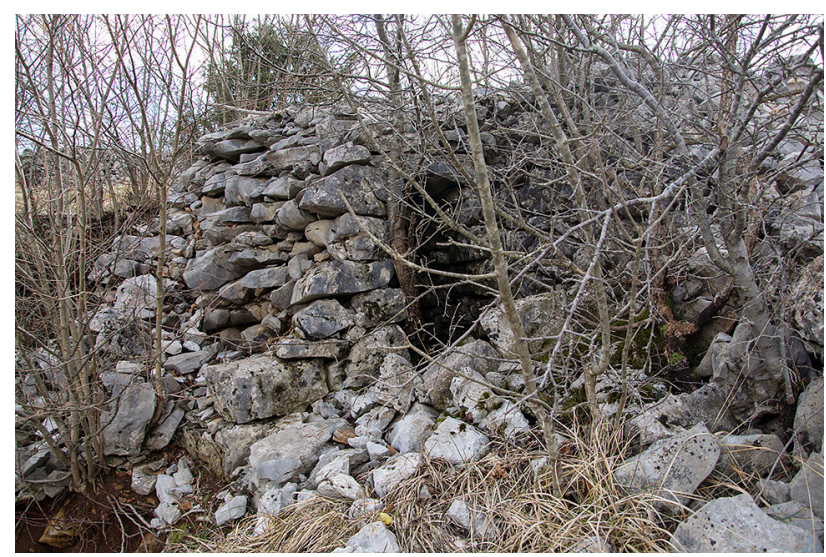

Figure 1. Most shelters are rather small and hidden (HIS_033).

Using a photographic pole (Figure 2) and a variety of cameras and lenses, sets of largely overlapping photographs with a predefined sampling distance were acquired for every shelter. These photographs depicted the shelter's interior and exterior as well as a set of coded targets and levels placed around every building. Distance measurements between the coded targets were used to accurately scale the 3D surface models extracted from those photographs, while the depicted levels and a compass reading enabled their correct orientation.

Although the cost-effective documentation approach proved to be well-suited for the heritage-specific aims of this research, acquiring and processing the photographs was not always that straightforward. The interior of these shelters does not allow to move around with a camera comfortably. The right side of Figure 2 shows a shelter with a somewhat larger interior, but on average, the interior is only $1.4 \mathrm{~m}$ high and $1.1 \mathrm{~m}$ in diameter.

On-camera LED-based artificial light was used to overcome the large illumination differences between the outside and the inside parts of the shelter, while also enabling a high enough shutter speed for handholding the camera inside the construction (Figure 2 ). Although the focal length, principal distance and aperture were kept fixed throughout the photography session, the in- and outdoor acquisition featured own parameter sets to enable an appropriate focus and depth of field.

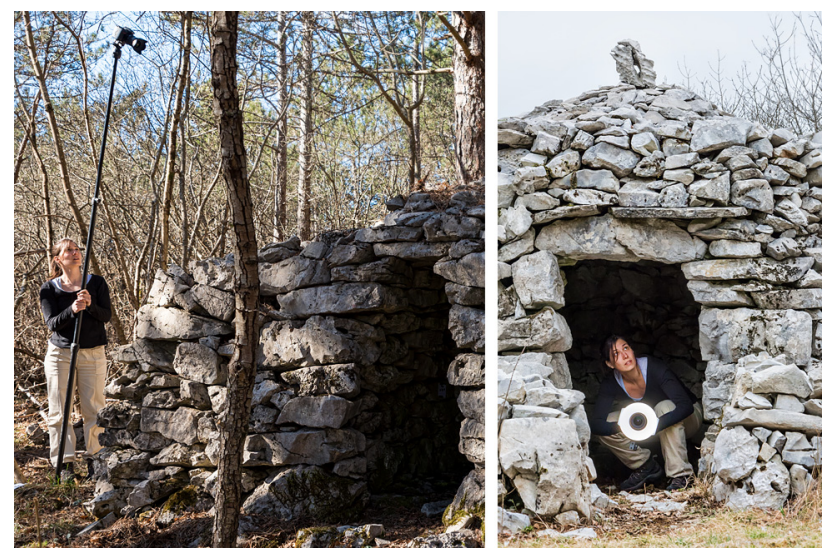

Figure 2. Photographing dry-stone shelters using a photographic pole (HIS_043) and artificial illumination (HIS_039).

It was decided that every $3 \mathrm{D}$ model should depict surface details of at least $5 \mathrm{~mm}$ to achieve the necessary amount of digital geometrical detail for this study. Given that about three pixels (i.e. 1.5 times the Nyquist rate) are needed to resolve a feature in most situations properly, a Scene Sampling Distance or SSD of maximally $2 \mathrm{~mm}$ was aimed for. In the end, the average SSD for all documented shepherd shelters equalled $0.5 \mathrm{~mm}$, with a maximum value of $0.8 \mathrm{~mm}$ for HIS_009. These values are reported by Agisoft PhotoScan Professional (which was used for all the image-based modelling) and are computed either as an average from all pixels of all depth maps, or as an average across all images whereby the image-specific value equals the median distance from the image centre to all tie points present in that image (pers. comm. Dmitry Semyonov, Agisoft). The acquired imagery was thus more than sufficient for the intended purpose, while the small SSDs even allowed to overcome image softening due to lens aberrations and diffraction effects (Verhoeven, 2016).

Very often, large amounts of vegetation had to be cut before the image acquisition could start. For some shelters, the vegetation was so dense that certain parts could not be reached and - as such - remained unmodelled (e.g. Figure 1). The numerous cavities between the stones meant that hundreds of photographs had to be taken to avoid occlusion zones as much as possible. The cavities themselves are rendered as pure black tones in most images, which meant that they could not be adequately modelled.

In some cases, the shelter was part of a larger complex. Since the documentation of such constructions lasted many hours, significant differences in illumination were unavoidable during photo acquisition. To counteract those, all photos were acquired as 14-bit NEF files (Nikon's RAW format) and converted into 16-bit uncompressed TIFFs using Adobe Lightroom. Part of this development was to lift the image detail in the shadows and bring back details in the highlights for the whole image collection. It is due to the high dynamic range of modern digital cameras and powerful RAW development software that such equalisation steps are possible nowadays (Figure 3 ).

\subsubsection{Two-manifold, decimated and watertight meshes}

After computing the image-based 3D models in various versions of PhotoScan Professional, mesh errors such as small holes and non-manifold areas were fixed in 3D Systems' Geomagic Studio 2013. Since millions of facets usually characterised these meshes, all 3D models were decimated at this stage to ensure their 
straightforward use in downstream applications. Given that this mesh decimation should balance the total facet count with the loss of morphological details, a $2 \mathrm{~mm}$ tolerance-based simplification was executed within Atangeo Balancer nPro. Whereas this small piece of software can deliver accurate and error-controlled mesh reductions (Verhoeven, 2017), the specific tolerance number relates to the above-mentioned desirable SSD.
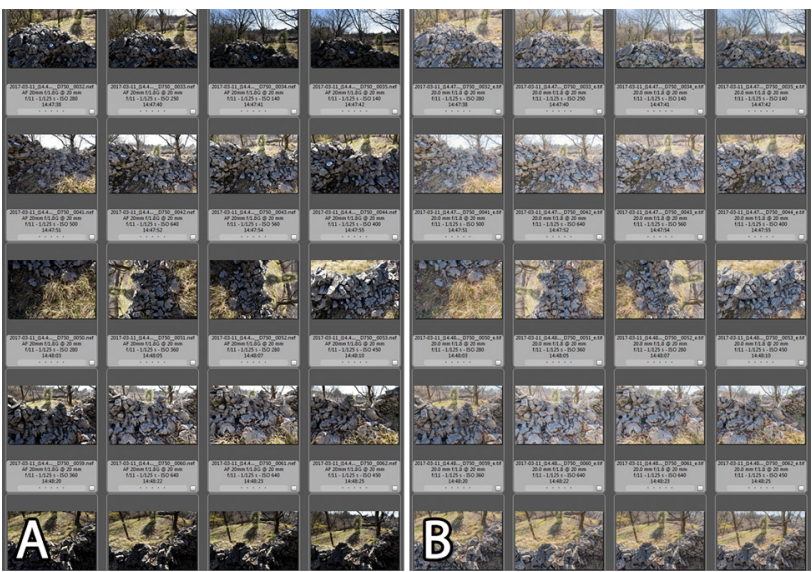

Figure 3. A) displays a subset of unprocessed NEFs, while B) shows the same set of photographs processed into 16-bit TIFFs.

Finally, the shelter had to be isolated from its environment and its bottom part closed, since the total volume of the shelter had to be computed. Both operations proved to be much more problematic than initially thought. Very often, the exact borders of the shelter were not easy to discriminate, due to the vegetated undulating terrain around it or because the shelter is embedded into another dry-stone construction (such as a wall - Figure 4A \& 4B).

In addition, it was not always easy to distinguish to what extent the first rows of stones are buried under the present-day walking surface, while the interior part was often located below the first row of visible stones (Figure 4C). Third, some parts of the shelter could often not be reached (e.g. those embedded into another stone structure or shielded by trees), which means that certain sections had to be modelled from scratch using the 'most plausible' principle (Figure 4C \& 4D). A last cycle of error repair finalised this whole modelling process, which yielded a digital surface approximation for every shelter in the form of a reduced, watertight and two-manifold triangular mesh (Figure 4D).
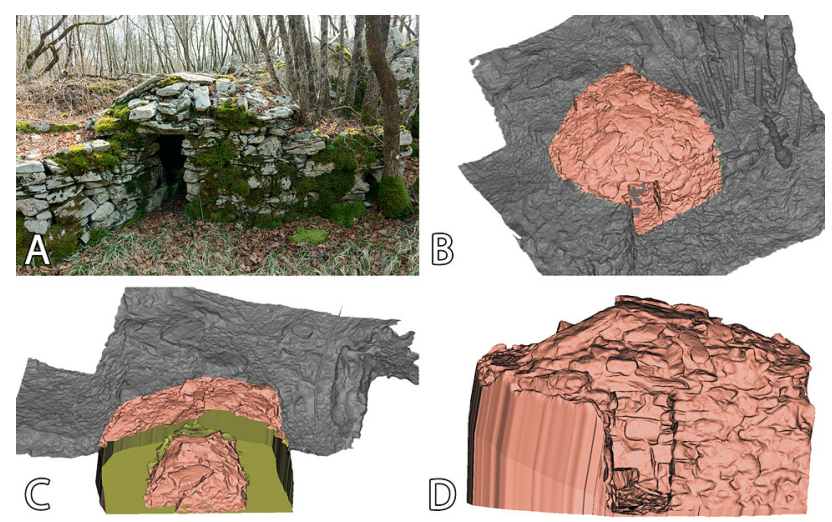

Figure 4. A) depicts shelter HIS 013 as part of a dry-stone wall. To estimate the shelter's stone volume, one has to B) separate the shelter from the wall, and C) close this hole plus the bottom part. D) shows the final watertight triangular 3D surface mesh.

\subsection{Deriving volume and total stone mass of the shelter}

\subsubsection{Stone volume}

These closed artefact-free surfaces were subsequently used to compute the total volume of stones needed to build every shelter. However, and as mentioned in section 2, dry-stone architecture with irregularly shaped stones brings many construction cavities along. According to the literature (Mundell et al., 2009), these small and countless cavities can account for up to $20 \%$ to $40 \%$ of the total construction volume. The volume computed from the closed 3D mesh was therefore reduced with $30 \%$ to approximate the volume of actual building material. The volume of effective stone material used to construct the shelters is reported in Figure 6 . For three shelters, these volume calculations were not possible because the constructions were either collapsed or shielded from too many sides to get a decent approximation of the outer surface.

\subsubsection{Volumetric mass density and total mass}

To calculate the total stone mass of every shelter from these building material volumes, the volumetric mass density (or simply density) of this type of limestone must be known. For Kras, the limestone density $\rho$ commonly varies from $2100 \mathrm{~kg} / \mathrm{m}^{3}$ to $2870 \mathrm{~kg} / \mathrm{m}^{3}$ (Mirtič et al., 1999). To get a more specific result, it was decided to compute the density from stones lying around these shelters. In total, three medium stones were collected and their surface digitally extracted inside PhotoScan Professional. After scaling the watertight meshes with three distances that exceeded the stone's dimensions, the volume of every stone was extracted. Next, every stone was weighted three times on two different balances, and the six results averaged. Using their volume $V$ and mass $m$ data, the density $\rho$ of each stone was obtained using:

$$
\rho=\frac{m}{V}
$$

Finally, averaging the three densities yielded a value of 2718 $\mathrm{kg} / \mathrm{m}^{3}$, a number that falls within the range reported in the literature. With the help of this value, the mass of every shelter's building material could be computed (see Figure 6).

\subsection{Deriving building cost}

With the total stone volume and mass as input, this section will derive two types of building cost per shelter: the time it took to build it (i.e. labour-time cost - section 2.3.1) and the amount of caloric energy that was expended during its construction (i.e. the metabolic cost - section 2.3.2). The latter will be estimated from a biomechanical abstraction of the whole shelter building process. These types of cost assume that the building material was already lying in the direct vicinity of the location on which the shelter would be built. The time and caloric energy to find and fetch the stones is thus not part of these quantifications.

Both types of cost computation can be labelled as architectural energetics, an approach that became popular after the seminal book "How the Maya built their world. Energetics and ancient architecture" by Elliot Abrams (Abrams, 1994). Although Abrams' idea of architectural energetics was not new, his book clarified, applied and disseminated the concept of estimating the composite 'energetic cost' of constructing architectural works. However, his cost quantification was labour-time expenditure in person-days. Abrams later restated this, summarising energetics as the estimation of a building's labour-time cost using timed experiments or observations of building activities (Abrams and Bolland, 1999). The present paper will thus broaden this initial 'cost' concept and try to understand the specific temporal and metabolic costs involved in erecting these dry-stone shelters. 


\subsubsection{Labour-time cost}

As a result of the limestone density measurements, the average mass of a stone was decided to be $5 \mathrm{~kg}$. Dividing the shelter's total stone mass by the mass of this 'average' stone yielded an estimate for the total number of stones $N_{\text {stones }}$ per shelter (see Figure 6). With this number and assuming a thirty-second handling time per stone, the total building time was calculated. This handling period was indicated by timed experiments and assumed that the stones were lying in the direct vicinity. The stone-handling interval thus encompasses the time needed to pick the correct stone, lift it vertically from rest, place it on a suitable location and adjust its final position.

Afterwards, the total building time expressed in seconds was converted to person-days, thereby assuming eight hours of labour. Most likely, these shepherds could easily spend twelve hours per day, but resting for four hours in between seems very reasonable, just because the construction of those shelters was not a competitive activity or a dedicated full-body workout.

\subsubsection{Metabolic cost}

Deriving the mathematical formulation to compute this metabolic cost asks for a dive into the world of classical mechanics. This branch of physics deals with the study of motion and the related concepts of force and mass (Tipler and Mosca, 2008). It covers both the description of motion and the study of the forces that cause it, but only for macroscopic objects and speeds that are not very large. Over time, these classic principles also found application in biomechanics, an academic discipline defined as "the study of the structure and function of biological systems by means of the methods of mechanics" (Hatze, 1971). This paper will draw from the conceptual and mathematical tools of biomechanics to model the total energy expenditure of a shepherd's body in erecting a dry-stone shelter.

The chemical energy that is stored inside food and - after digesting this food - inside the muscles, enables a human to do work. In classical physics, work - or more correctly mechanical work - is done on an object when an external force is exerted on that object causing it to move some distance (Young et al., 2012). Without movement, there is no work even though the exerted force can be enormous (e.g. trying to move a $600 \mathrm{~kg}$ rock). In that sense, the physical meaning of work is unique compared to its regular conversational use. In its most general mathematical form, mechanical work $W$ is expressed in joule $(\mathrm{J})$ and defined as an integration of force $\vec{F}$ (expressed in newton $\mathrm{N}$ ) over a displacement $\vec{s}$ (expressed in $\mathrm{m}$ ):

$$
W=\int \vec{F} \cdot d \vec{s}
$$

To raise a stone vertically from rest to a certain height $h$ above the ground, the shepherd must exert an external force upon it. Since this applied force should oppose the gravitational pull on the stone, it is possible to replace the acting force $\vec{F}$ in (2) by the Earth's gravitational force $\vec{F}_{\text {gravity }}$, while the magnitude of the displacement $\vec{s}$ equals height $h$ (initially $h=0$ for all stones; see Figure 5). The omnipresent force of gravity is the product of mass $m$ (expressed in $\mathrm{kg}$ ) and the gravitational acceleration $\vec{g}$, which equals $9.81 \mathrm{~m} / \mathrm{s}^{2}$ at the Earth's surface.

$$
\vec{F}_{\text {gravity }}=m \vec{g}=\vec{w}
$$

Equation (3) shows that all objects on Earth experience a downward pulling force proportional to the mass of the object, a quantity more commonly known as the weight $\vec{w}$ of the object. For instance, a stone with a mass of $10 \mathrm{~kg}$ weights $98 \mathrm{~N}$. Because $\vec{g}$ changes only little with height, its magnitude $g$ is assumed constant and can be moved in front of the integral alongside the mass $m$. The above equation (2) thus becomes:

$$
W=\int F_{\text {gravity }} d h=m g \int d h
$$

Therefore, the work $W$ that is needed to lift a stone vertically from rest a certain distance equals the product of the stone's mass $m$, the gravitational acceleration $g$ (against which the stone has to move) and the integral of the height $h$ that stone has to be raised to. Finally, the vertical component of the shelter's Centre of Mass (CoM) can be used to reduce (4) to a simple product:

$$
W=m g h_{\text {CoM_ } \_ \text {shelter }}
$$

Put in another way, (5) tells that the work a shepherd has to put into lifting all the construction stones of a shelter is the same as if he would lift the shelter's total mass to its CoM. The correct nature of this reasoning can be illustrated by imagining three stones, each having a mass of $1 \mathrm{~kg}$. Lifting two stones $1 \mathrm{~m}$ high and leaving the third one the ground demands $19.6 \mathrm{~J}$ of work:

$$
W=(2 \mathrm{~kg})\left(9.81 \mathrm{~m} / \mathrm{s}^{2}\right)(1 \mathrm{~m})+(1 \mathrm{~kg})\left(9.81 \mathrm{~m} / \mathrm{s}^{2}\right)(0 \mathrm{~m})=19.6 \mathrm{~J}
$$

Lifting all three stones to their total CoM also yields $19.6 \mathrm{~J}$ :

$$
W=(3 \mathrm{~kg})\left(9.81 \mathrm{~m} / \mathrm{s}^{2}\right) \frac{0 \mathrm{~m}+2(1 \mathrm{~m})}{3 \mathrm{~m}}=19.6 \mathrm{~J}
$$

Under all abovementioned assumptions, deriving the necessary work $W_{\text {lifting_stones }}$ to raise all the stones of a dry-stone shelter can thus be accomplished using the following simple formula:

$$
W_{\text {lifting_stones }}=m_{\text {shelter }} g h_{\text {CoM_shelter }}
$$

For the first shelter (HIS_001), this boils down to:

$$
W_{\text {lifing_stones }}=\left(22.4 \times 10^{3} \mathrm{~kg}\right)\left(9.81 \mathrm{~m} / \mathrm{s}^{2}\right)(0.88 \mathrm{~m})=193 \mathrm{~kJ}
$$

However, (6) needs a few alterations to make the computation more accurate. First, using the height of the shelter's CoM results in a too low number. In order to place a book on a shelf, one needs to lift the book higher than the shelf level. Similarly, lifting construction stones requires one to lift the stones slightly higher than the actual height they will be deposited at. Here, an additional $0.15 \mathrm{~m}$ is therefore included, yielding:

$$
W_{\text {lifting_stones }}=m_{\text {shelter }} g\left(h_{\text {CoM_shelter }}+0.15 \mathrm{~m}\right)
$$

This changes the number for HIS_001 to $226 \mathrm{~kJ}$. Second, this quantification of the shepherd's building work expresses the absolute minimum amount of work because it merely equals the work needed to separate the stones from the ground by opposing gravity. Since the force applied by the shepherd and the stones' displacement have the same direction, the resulting work is said to be positive (work which gets stored in the form of increased gravitational potential energy). However, the gravitational force is said to do negative work on the stone, because it acts in a direction that is opposite to its displacement. This implies that the total work done on the stone is zero. As an example: an $98 \mathrm{~N}-$ applied force to lift a stone of ten kilogram versus the 
gravitational force of $-98 \mathrm{~N}$ acting upon the stone. Both forces have the same magnitude $(F=98 \mathrm{~N})$, but opposite directions. Note that (7) does not say anything about how long it takes to do the work, only because the definition of work does not include duration. To express the rate of work, one would need to compute power, in $\mathrm{J} / \mathrm{s}$ or watt $(\mathrm{W})$.

Equation (7) expresses the so-called external work, being the positive mechanical work needed to lift the total stone mass. Although it might seem a fair way to estimate the energy expenditure, it does not include the work done about the joints to lift the body's own mass. This is sometimes referred to as internal work (Winter, 2009). Taking internal work accurately into account is very complicated. One of the difficulties is related to the work efficiencies of muscle contractions. Scholars have attempted to model and measure internal work - mainly for gait - but it remains tough to get accurate results.

A straightforward way to incorporate internal work for lifting is to look at the vertical movement of the body's CoM, a method often used to analyse walking (Cavagna and Margaria, 1966). Despite its limitations (e.g. one computes only the vertical work of the body), this method has been used before in physiological studies of lifting (Sharp et al., 1988; Welbergen et al., 1991). Given that no other practicable approach to compute the internal work during a lift seems to have been proposed in the scientific literature, this paper proposes the following formula to approximate the work needed for raising the body:

$$
W_{\text {lifting body }}=N_{\text {stones }}\left(m_{\text {body }} g h_{\text {CoM_body }}\right)
$$

where the number of stones $N_{\text {stones }}$ quantifies how many times the shepherd has to lift his body mass $m_{\text {body. To find an appropriate }}$ value for $h_{\mathrm{CoM}}$ body (i.e. the vertical displacement of the body's $\mathrm{CoM}$ ), one has to consult the physiological literature. Various studies focused on the influence of technique, loads, frequencies and height range of repetitively lifting objects. In essence, there are two main manual lifting techniques: the stoop lift (with straight legs and bent back - Figure 5) and the squat lift (with flexed knees and erect back). Sometimes, a freestyle technique with flexing knees and back is also considered (Kumar, 1984). It has been shown that for repetitive lifting of objects, squat lifting is significantly more costly than the stoop lift regarding energy expenditure when raising the same load with the same frequency (Garg and Saxena, 1979; Welbergen et al., 1991). Because the squat lift comes with a smaller energy cost, people are much more inclined to lift objects with straight legs and a bent back in daily work. Some experiments also showed that people shift from a squat to a stoop lifting technique when fatigue starts to develop (Resnick, 1996; van Dieën et al., 1998).

The squat lift owes it more significant cost in large part due to the greater vertical displacement of the body's CoM and the higher internal energy losses. Welbergen et al. (1991) reported a $32 \mathrm{~cm}$ average vertical displacement of the body's CoM for stoop lifting, whereas squat lifting resulted in $46 \mathrm{~cm}$ [note that the paper mentions $46 \mathrm{~mm}$, which must be erroneous since the authors mention later that the CoM travels $14 \mathrm{~cm}$ more in the squat lift]. Given that these numbers are resulting from a sample of nine men whose body height was on average $1.82 \mathrm{~m}$, one can deduce a vertical CoM displacements of $30 \mathrm{~cm}$ (stoop) for $19^{\text {th }}$ century shepherds with $1.7 \mathrm{~m}$ standing body heights (i.e. a usual male stature for that time - Hatton and Bray, 2010). This body CoM displacement also agrees with the illustrations in Murray et al. (1967). In addition, a rather lean body of $65 \mathrm{~kg}$ is assumed (Figure 5). At this point, equation (8) gives $856 \mathrm{~kJ}$ for HIS_001:

$$
W_{\text {lifting_body }}=4473(65 \mathrm{~kg})\left(9.81 \mathrm{~m} / \mathrm{s}^{2}\right)(0.3 \mathrm{~m})=856 \mathrm{~kJ}
$$

To model the total amount of mechanical work and use that quantity to estimate the builder's metabolic energy expenditure, this study assumes an energy balance between computed mechanical work and physiological work. However, (8) does not account for the energy cost of lowering the body. This omission is due to the specificity of lifting as an activity.

Traditionally, positive muscle work is defined as work done by shortening contractions in which the force and displacement vectors are in the same direction. A person that climbs a vertical ladder shortens his leg extensors, thereby doing positive work against gravity. Upon descending, the same muscles get lengthened while actively resisting the gravitational pull. In that case, the muscles are said to do negative work (Abbott et al., 1952; Kamon, 1970). One cycle of lifting the body mass comprises an up- and subsequent downward phase. During the lowering phase, the body does negative work since the muscles act against the weight by decelerating it. The positive work to higher the body's CoM is thus counteracted by the negative work associated with lowering it, leading to zero net mechanical work for one cycle of body mass lifting.

An assumed energy balance between mechanical work and physiological work would mean that the caloric expenditure also equals zero. This does not make sense, because it would make physiological work conservative. Moreover, it indicates that the term 'internal work' should best be discarded, since it carries too much baggage due to the uncertainties in energy recovery and the problems related to any negative work.

To solve this negative work-related problem, many earlier papers - and (8) - just ignored the body's lowering phase when computing energy expenditure resulting from a lifting task (Sharp et al., 1988; Welbergen et al., 1991). Even though the argument that 'gravity anyhow drives the downward body displacement' seems to lend plausible support to this decision, muscles are complex systems that also require metabolic energy to maintain tension throughout a controlled descent. Although it is known for many decades that negative work has a smaller physiological cost than positive work (Abbott et al., 1952; Kaneko et al., 1984) because fewer motor units are needed to develop the same force, not accounting for repetitive lowering of one's body mass would still seriously underestimate the total energy expenditure, thereby harming the assumed energy balance.

For some activities that include both positive and negative work components like running (Williams and Cavanagh, 1983) and climbing (Kamon, 1970), scholars estimated the proportional metabolic cost of negative versus positive work. The sum of the positive work and a proportion of the absolute negative work yields then the total physiological cost. The most realistic assessment to date of the relative caloric expenditure linked with the negative mechanical work in repetitive lifting stems from De Looze et al. (1994). They estimated the metabolic energy cost of lowering the body mass to be about 0.3 to 0.5 times the energy cost of the positive work. With this information (and after equalling the total stone mass to the average $5 \mathrm{~kg}$ stone times the number of stones), the total work equation can now be written:

$$
\begin{gathered}
W_{\text {total_work_lifting }}=W_{\text {upward_phase }}+W_{\text {downward_phase }}= \\
W_{\text {lifting_stones }}+W_{\text {lifting_body }}+W_{\text {lowering_body }}= \\
W_{\text {lifting_ttones }}+1.3 W_{\text {lifting_body }}= \\
N_{\text {stones }}\left(9.81 \mathrm{~m} / \mathrm{s}^{2}\right)\left((5 \mathrm{~kg})\left(h_{\text {CoM_sheter }}+0.15 \mathrm{~m}\right)+1.3(65 \mathrm{~kg})(0.3 \mathrm{~m})\right)
\end{gathered}
$$


Equation (9) quantifies all mechanical work as a combination of work needed to raise the stones vertically and work needed to move the body up and down to pick up and lift the stones (see also Figure 5). In reality, many more factors come into play when estimating the total work cost of building these shelters. Apart from non-gravitational influences in the lifting process (like stone friction and air resistance), there is also a small kinetic energy component that was not taken into account (see section 4.1).

Moreover, lifting the stones is but one aspect of the building process. The shepherds also need energy to hold the stones while determining their final position and reposition them. For example: holding a stone of $5 \mathrm{~kg}$ when looking for its ideal position will result in increased physiological work due to the 49 $\mathrm{N}$ pushing down on the body on the one hand, and the required muscle activation to not fall over on the other. Moreover, a stone could be lifted, and afterwards put down again upon noticing that it does not fit. To consider all these additional energy costs, a total work multiplier of two was added, yielding the following approximation for total dry-stone building work: $2 W_{\text {total_work_lifting. }}$

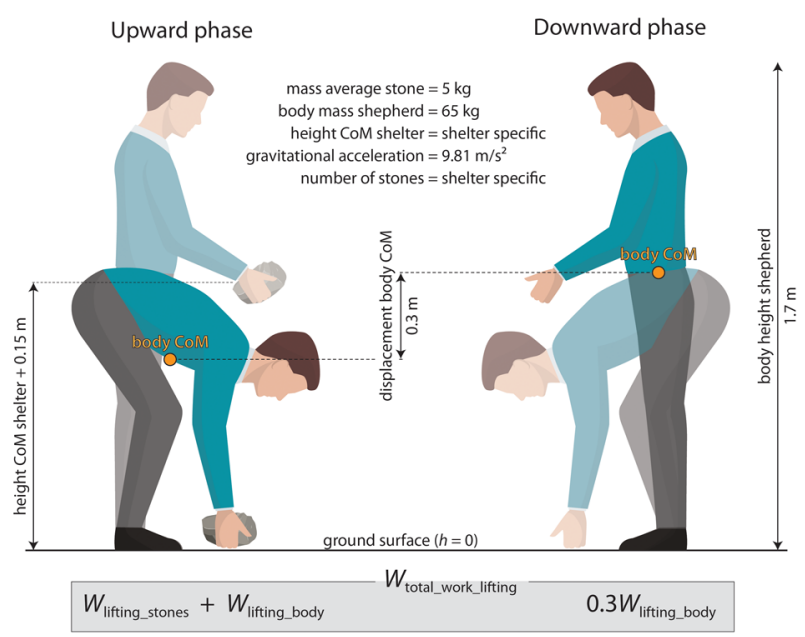

Figure 5. All the variables that are used in the biomechanical approach to estimate the builder's total lifting work.

Figure 6 depicts the results of this computation for all shelters. To interpret these numbers in terms of caloric expenditure (and thus necessary food intake), this building work (expressed in joules) must be converted to calories, a calorie (cal) being the amount of heat required to raise the temperature of one gram of water one Celsius degree $\left(1^{\circ} \mathrm{C}\right)$ (Whitney and Rolfes, 2016). Since heat is a measure of energy transfer, the calorie can be defined in terms of the standard energy unit: 1 calorie $=4.184 \mathrm{~J}$ (Tipler and Mosca, 2008). It is important to note that the dietary calorie or Calorie (written and abbreviated capitalised) nowadays used in describing the energy content of foods, is actually a kilocalorie (Serway and Jewett, 2004).

Finally, one must also take an energy efficiency factor $\eta$ into account. After food is ingested, its chemical energy is released and the cells of the human body can convert this chemical food energy into electrical energy (to send brain and nerve impulses), heat energy (to maintain a standard body temperature) and mechanical energy (to move the muscles) (Whitney and Rolfes, 2016). According to various sources, the human body converts the chemical food energy into mechanical energy with a $20 \%$ to $30 \%$ efficiency rate (Whipp and Wasserman, 1969). Here, $20 \%$ is assumed $(\eta=0.2)$. The energy content $E_{\text {food }}$ in kilocalories (kcal) of the food that a shepherd must consume to fuel his body for shelter building thus equals:

$$
E_{\text {food }}=\frac{2 W_{\text {total_work_lifting }}}{\frac{4184 \mathrm{~J}}{\mathrm{kcal}} \eta}
$$

Applying (10) to shelter HIS_001 yields 3199 kcal:

$$
E_{\text {food }}=\frac{2677 \mathrm{~kJ}}{\frac{4.184 \mathrm{~kJ}}{\mathrm{kcal}} 0.2}=3199 \mathrm{kcal}
$$

Dividing the results of (10) by the total building time (expressed in days) yields then the daily calories a shepherd expends during the construction of his shelter. This daily caloric cost is reported for every shelter in Figure 6, along with many other intermediate computations. The next section will cover these results and the practical implications of the energy requirement numbers.

\section{RESULTS}

The human body uses chemical energy stored in food to meet its energy requirements and fuel the myriad activities of all cells. In short, human Total Daily Energy Expenditure (TDEE) consists mainly of 1) the basal metabolism, which comprises essential life functions like cell replacement, the uninterrupted function of the brain, heart and respiratory muscles plus maintenance of the body temperature); 2) the ingestion and digestion of food (known as the thermic effect of food); 3 ) and physical activity, which is the most variable and the second largest component of the TDEE (Dunford and Doyle, 2008).

Accurately measuring the basal and activity-related metabolic rate is not feasible in everyday practice due to the required specialised equipment and restrictive measuring conditions, but the scientific literature holds different predictive equations to estimate these measures. A popular way is to first approximate the basal metabolic rate of adults by body mass, body height and age. Afterwards, the TDEE can be predicted by multiplying the basal rate with a score that quantifies the physical activity level. For a thirty-year old, 1.7 meter tall, sixty five kilogram inactive male, the TDEE boils down to 2200 Calories or $2200 \mathrm{kcal}$ when using the basal rate equation from Mifflin et al. (1990) and a physical activity level of 1.4 for sedentary persons (United Nations University et al., 2004).

The last column of numbers in Figure 6 equals the caloric content of the food a shepherd must daily eat in addition to the $2200 \mathrm{kcal}$ he needs to live an inactive, sedentary life. Adding about $660 \mathrm{kcal}$ on average, the TDEE of a shepherd would thus boil down to circa $2860 \mathrm{kcal}$. This value corresponds to a physical activity level of 1.8, which is categorised as 'a moderately active person' such as a construction worker (United Nations University et al., 2004). As such, the computed metabolic building cost seems sensible. Building these shelters was not that metabolically demanding, because shepherds did not engage in this activity to burn calories nor felt any pressure to build as quickly as possible.

The paper indicates that a shepherd's daily carbohydrate, protein, and fat intake did not need major modification to build such shelters. Although there is a $660 \mathrm{kcal}$ expenditure increase per day of building, his usual food intake of $2200 \mathrm{kcal}$ could suffice, as the human body can handle such a caloric deficit for a few days. Most likely, the bigger shelters were also built with more persons, thereby reducing the building time. Only when a shelter would need more than a few person-days to build, could a slight loss in body mass occur if no additional calories were consumed. 


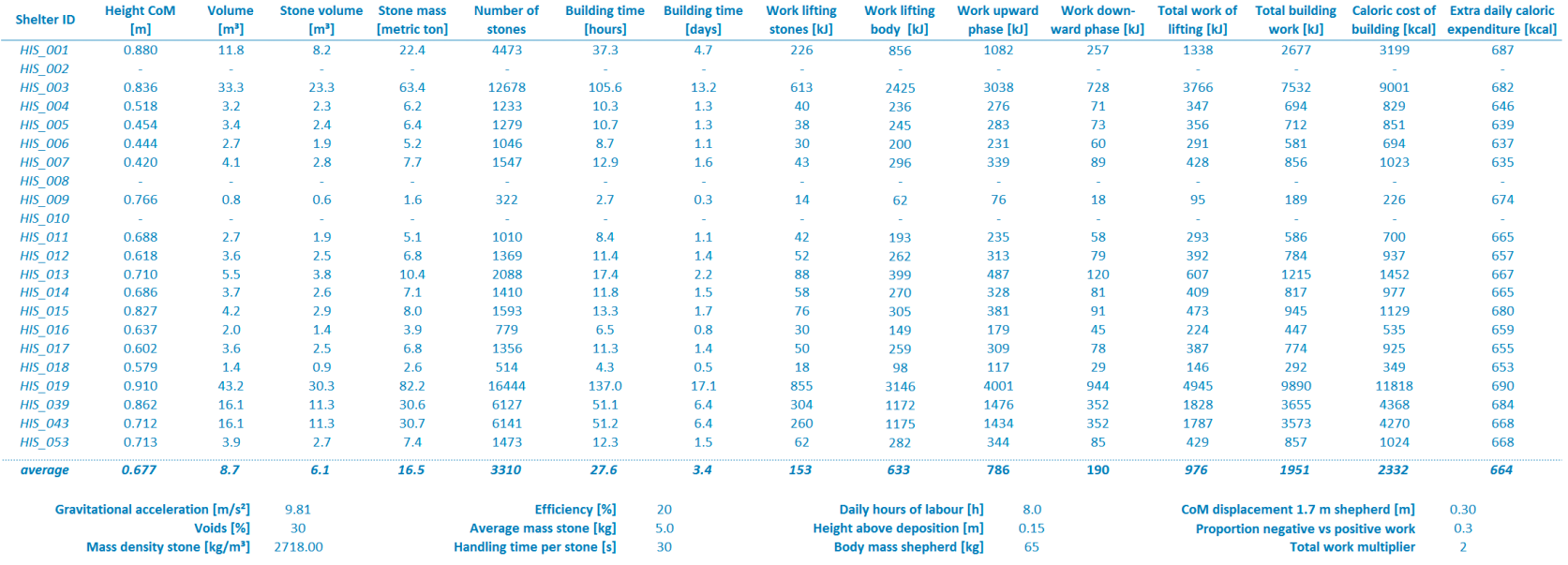

Figure 6. This figure tabulates all the shelter-specific derived data and provides the values of the variables used in the equations.

\section{DISCUSSION}

\subsection{The subjectivity of 3D models}

Documenting tangible cultural heritage involves gathering the right (amount of) data about real, physical objects. In this era of archaeological 3D datafication, it seems that the geometrical or spatial component of cultural heritage gets documented almost exclusively. Moreover, many scholars assume that digital 3D surface models are inherently or explicitly of greater importance than their analogue counterparts, because their (potential for) high geometrical accuracy renders them 'more objective'.

This paper has, however, shown that there is no such thing as objectivity when it comes to 3D models. The choice of documenting a specific building, the use of a particular laser scanner or camera and lens to acquire a pre-defined or random SSD are all very subjective decisions. Even if all the image acquisition parameters would be standardised, subjectivity takes still a leading role since experience, a priori knowledge, and intuition govern the data processing, 3D model optimisation, visualisation, interpretation, and information synthesis.

As mentioned in the very beginning of the paper, many technical and methodological issues had to be considered during the data post-processing phase that lead to the final 3D surface models for the volumetric analysis. It was often challenging to estimate the correct dimensions of a shelter. Even though their exterior orientation could sufficiently be established through the incorporation of levels in the images, delineating shelters from their natural environment or shared dry-stone constructions is complicated. Most likely, two people would end up with different delineations, which could be problematic because they impact the computation of the shelter's volume and its CoM location.

Even if one would agree on a shelter's borders, there is still subjectivity involved with its closure. The central portion of the shelter is usually deepened over time due to usage, allowing for multiple options to connect the outer walls to the inner walls in order to yield a volume. Each of these critical decisions adds another level of arbitrariness to the final surface model upon which the computations are based. Moreover, this is even before one starts to interpret the derived data.

This paper relied upon 3D models for direct shelter measurements (e.g. volume, $\mathrm{CoM}$ ) and indirect measurements that are in part based on the former (like the total stone mass and the number of stones) to compute the temporal and metabolic costs that went into their analogue construction. Both costs also relied upon a handful of equations and variables that are simplifications or best guesses, respectively (see section 4.2). So, although this paper clearly showed that a considerate application of architectural 3D surface models could easily transcend their frequent use as communication or educational material, the reliance upon subjectivity will always remain unavoidable.

\subsection{Equation accuracy}

The caloric cost equation derived with simplified biomechanical and physiological principles should not be considered a fixed rule. It only forms a computational and interpretative guide which can be used in the energetics study of such dry-stone constructions. It remains very difficult - if not impossible - to account for construction skills, lifting position of the body, the effectiveness of the different muscles involved and the working conditions (e.g. clothing, weather, physical and psychological state). All these variables influence the final metabolic cost estimation, but many of them will always remain incalculable. That is why this study often had to rely on assumptions. Published data guided some of them (e.g. the stature of the shepherd and the percentage of voids in the shelter), but many others are estimates that are the product from - what is hoped to be - sensible consideration (such as the shepherd's body mass or the total work multiplication factor).

One factor that (9) could include is translational kinetic energy. Now, it is assumed that the stones arrive at their final position with zero speed. Computing the total mechanical work to erect a shelter with a very modest final speed of $1.6 \mathrm{~m} / \mathrm{s}$ for the lifted stones (a value from Kingma et al. (1995)), would lead to an average $15 \mathrm{~kJ}$ or $2.2 \%$ increase in computed work. Because the inclusion of kinetic energy would only marginally alter the TDEE and its contribution is smaller than the probable errors involved in estimating some of the other parameters, it was excluded.

\section{CONCLUSION}

This paper showcased how analysing 3D surface models of small stone constructions can lead to new archaeological insights. In particular, conclusions could be drawn about the architectural energetics in terms of building-time and energy expenditure. This approach is novel for many reasons. First, the metabolic cost was computed and not only the typical labour-time cost in person- 
days. Second, the biomechanical abstraction of the lifting process united the force applied on the stones with the physiological cost of raising and lowering the body mass; third, these caloric values were compared with the result from a standard physiological equation which estimates the TDEE based on a person's age and anthropometrics. Nevertheless, this paper should only be seen as a starting point to come to realistic, building-task specific metabolic costs on the basis of 3D surface models. A follow-up paper will build upon these physical abstractions and expand the modelling to include all construction steps (like stone collecting).

\section{ACKNOWLEDGEMENTS}

The authors are grateful to Boris Čok for sharing his knowledge about these shelters and his assistance in locating many of them.

\section{REFERENCES}

Abbott, B., Bigland, B., Ritchie, J., 1952. The physiological cost of negative work. J. Physiol. 117(3), pp. 380-390.

Abrams, E., 1994. How the Maya built their world. Energetics and ancient architecture. University of Texas Press, Austin.

Abrams, E., Bolland, T., 1999. Architectural Energetics, Ancient Monuments, and Operations Management. J. Archaeol. Method Theory 6(4), pp. 263-291.

Cavagna, G., Margaria, R., 1966. Mechanics of walking. J. Appl. Physiol. 21(1), pp. 271-278.

De Looze, M., Toussaint, H., Commissaris, D., Jans, M., Sargeant, A., 1994. Relationships between energy expenditure and positive and negative mechanical work in repetitive lifting and lowering. J. Appl. Physiol. 77(1), pp. 420-6.

Dunford, M., Doyle, J., 2008. Nutrition for sport and exercise, Student edition. Thomson Wadsworth, Belmont.

Garg, A., Saxena, U., 1979. Effects of lifting frequency and technique on physical fatigue with special reference to psychophysical methodology and metabolic rate. Am. Ind. Hyg. Assoc. J. 40(10), pp. 894-503.

Hatton, T., Bray, B., 2010. Long run trends in the heights of European men, $19^{\text {th }}-20^{\text {th }}$ cent. Econ. Hum. Biol. 8(3), pp. 405-13.

Hatze, H., 1971. Was ist Biomechanik? LeibesübungenLeibeserziehung 2, pp. 33-34.

Juvanec, B., 2016. Hiška. Pastirsko zatočišče na Krasu. Univerza v Ljubljani Fakulteta za arhitekturo, Ljubljana.

Kamon, E., 1970. Negative and positive work in climbing a laddermill. J. Appl. Physiol. 29(1), pp. 1-5.

Kaneko, M., Komi, P., Ossi, A., 1984. Mechanical efficiency of concentric and eccentric exercises with medium to fast contraction rates. Scand. J. Sports Sci. 6(1), pp. 15-20.

Kingma, I., Toussaint, H., Commissaris, D., Hoozemans, M., Ober, M.J., 1995. Optimizing the determination of the body center of mass. J. Biomechanics 28(9), pp. 1137-1142.

Kumar, S., 1984. The physiological cost of three different methods of lifting in sagittal and lateral planes. Ergonomics 27(4), pp. 425-433.
Mifflin, M., St Jeor, S., Hill, L., Scott, B., Daugherty, S, Koh, Y., 1990. A new predictive equation for resting energy expenditure in healthy individuals. Am. J. Clin. Nutr. 51(2), pp. 241-247.

Mirtič, B., Mladenovič, A., Ramovš, A., Senegačnik, A., Vesel, J., Vižintin, N., 1999. Slovenski naravni kamen. Ministrstvo za znanost in tehnologijo, Ljubljana.

Mundell, C., McCombie, P., Bailey, C., Heath, A., Walker, P., 2009. Limit-equilibrium assessment of drystone retaining structures. Proc. Inst. Civil Eng. Geot. Eng. 162(4), pp. 203-212.

Murray, M., Seireg, A., Scholz, R., 1967. Center of gravity, center of pressure, and supportive forces during human activities. J. Appl. Physiol. 23(6), pp. 831-838.

Resnick, M., 1996. Postural changes due to fatigue. Comput. Ind. Eng. 31(1-2), pp. 491-494.

Serway, R., Jewett, J., 2004. Physics for scientists and engineers, Sixth edition. Thomson-Brooks/Cole, Belmont.

Sharp, M., Harman, E., Vogel, J., Knapik, J., Legg, S., 1988. Maximal aerobic capacity for repetitive lifting. Comparison with three standard exercise testing modes. Eur. J. Appl. Physiol. Occup. Physiol. 57(6), pp. 753-760.

Štuhec, S., 2014. Tridimenzionalno dokumentiranje suhozidne arhitekture Krasa in Istre. Arheo 31, pp. 49-68.

Tipler, P., Mosca, G., 2008. Physics for scientists and engineers, Sixth edition. W. H. Freeman and Company, New York.

United Nations University, World Health Organization, Food and Agriculture Organization of the United Nations, 2004. Human energy requirements. FAO, Rome.

van Dieën, J., van der Burg, P., Raaijmakers, T., Toussaint, H., 1998. Effects of repetitive lifting on kinematics: Inadequate anticipatory control or adaptive changes? J. Mot. Behav. 30(1), pp. 20-32.

Verhoeven, G., 2016. Basics of photography for cultural heritage imaging. In: Stylianidis, E., Remondino, F., 3D Recording, Documentation and Management of Cultural Heritage. Whittles Publishing, Caithness, pp. 127-251.

Verhoeven, G., 2017. Mesh Is More-Using All Geometric Dimensions for the Archaeological Analysis and Interpretative Mapping of 3D Surfaces. J. Arch. M. Theory 24(4), pp. 999-1033.

Welbergen, E., Kemper, H., Knibbe, J., Toussaint, H., Clysen, L., 1991. Efficiency and effectiveness of stoop and squat lifting at different frequencies. Ergonomics 34(5), pp. 613-624.

Whipp, B., Wasserman, K., 1969. Efficiency of muscular work. J. Appl. Physiol. 26(5), pp. 644-648.

Whitney, E., Rolfes, S., 2016. Understanding nutrition, Fourteenth edition. Cengage learning, Stamford.

Williams, K., Cavanagh, P., 1983. A model for the calculation of mechanical power during distance running. J. Biomechanics 16(2), pp. 115-128.

Winter, D., 2009. Biomechanics and motor control of human movement, Fourth edition. John Wiley \& Sons, Hoboken.

Young, H., Freedman, R., Ford, A., 2012. Sears and Zemansky's university physics, Thirteenth edition. Addison-Wesley, San Francisco. 